\title{
Elaboration and Validation of the Medication Prescription Safety Checklist $^{1}$
}

\author{
Aline de Oliveira Meireles Pires² \\ Maria Beatriz Guimarães Ferreira ${ }^{3}$ \\ Kleiton Gonçalves do Nascimento ${ }^{4}$ \\ Márcia Marques dos Santos Felix ${ }^{5}$ \\ Patrícia da Silva Pires ${ }^{6}$ \\ Maria Helena Barbosa ${ }^{7}$
}

\begin{abstract}
Objective: to elaborate and validate a checklist to identify compliance with the recommendations for the structure of medication prescriptions, based on the Protocol of the Ministry of Health and the Brazilian Health Surveillance Agency. Method: methodological research, conducted through the validation and reliability analysis process, using a sample of 27 electronic prescriptions. Results: the analyses confirmed the content validity and reliability of the tool. The content validity, obtained by expert assessment, was considered satisfactory as it covered items that represent the compliance with the recommendations regarding the structure of the medication prescriptions. The reliability, assessed through interrater agreement, was excellent $(\mathrm{ICC}=1.00)$ and showed perfect agreement $(K=1.00)$. Conclusion: the Medication Prescription Safety Checklist showed to be a valid and reliable tool for the group studied. We hope that this study can contribute to the prevention of adverse events, as well as to the improvement of care quality and safety in medication use.
\end{abstract}

Descriptors: Patient Safety; Medication Errors; Drug Prescriptions.

\footnotetext{
${ }^{1}$ Paper extracted from Master's Thesis "Security on prescription medication in a teaching hospital", presented to Universidade Federal do Triângulo Mineiro, Uberaba, MG, Brazil.

2 MSc.

${ }^{3}$ Post-doctoral fellow, Universidade Federal do Triângulo Mineiro, Uberaba, MG, Brazil.

${ }^{4}$ MSc, RN, Hospital de Clínicas, Universidade Federal do Triângulo Mineiro, Uberaba, MG, Brazil.

${ }^{5}$ Doctoral student, Universidade Federal do Triângulo Mineiro, Uberaba, MG, Brazil. Scholarship holder at Coordenação de Aperfeiçoamento de Pessoal de Nível Superior (CAPES), Brazil.

6 PhD, Adjunct Professor, Instituto Multidisciplinar em Saúde, Universidade Federal da Bahia, Vitória da Conquista, BA, Brazil.

PhD, Associate Professor, Universidade Federal do Triângulo Mineiro, Uberaba, MG, Brazil.
}

\section{How to cite this article}

Pires AOM, Ferreira MBG, Nascimento KG, Felix MMS, Pires PS, Barbosa MH. Elaboration and Validation of the Medication Prescription Safety Checklist. Rev. Latino-Am. Enfermagem. 2017;25:e2921. [Access _f f _ ]; Available in: DOI: http://dx.doi.org/10.1590/1518-8345.1817.2921. month day year 


\section{Introduction}

In recent years, concerns with patient safety have emphasized the aspect of risk management associated with medication use ${ }^{(1)}$. Medicines are products capable of preventing, diagnosing, curing illnesses or relieving symptoms, but countless errors occur in the medication treatment process the patients receive(2).

One of the main adverse events hospitalized patients are victims of are medication errors, representing a severe problem in health services, besides being frequent ${ }^{(3-4)}$ and common in all health institutions due to the complexity of the process. It can happen in the prescription, dispensing or administration of medicines and is established as one of the causes of iatrogenic effects ${ }^{(5)}$.

The Conselho Nacional de Coordenação de Relatórios e Prevenção de Erros de Medicamentos (National Coordinating Council for Medication Error Reporting and Prevention - NCCMERP) defines medication error as an avoidable event, which can lead to the bad use of medication or to patient damage while the patient is under the professional's control(6).

Based on an analysis of the contribution of medical errors to deaths in the United States of America, it was estimated through research that medical errors can represent approximately 251 thousand deaths per year in the country, ranking third. Error is considered as an unintentional act, which did not produce the desired outcome, as well as execution or planning errors or failures in the care process $^{(7)}$.

The most sensitive method to identify medication dispensing and administration errors is observation, while the review of records is considered more appropriate to identify errors in medication prescriptions ${ }^{(8)}$. Among the different medication errors, prescription errors stand out due to their potential to cause harmful consequences to the patients ${ }^{(9)}$ and because they represent a considerable proportion of avoidable drug-related problems ${ }^{(10)}$.

The prescription process is complex and permeated by errors ${ }^{(11)}$. Prescription errors happened in $14.7 \%$ of the medication prescriptions in the United Kingdom, the most common being omission, wrong dose and incomplete prescription ${ }^{(12)}$.

The medical prescription is the reference document that guides and influences the other phases of the medication process. It is an essential communication tool among health professionals(11) and plays an important role in the prevention and occurrence of errors ${ }^{(13)}$.

An analysis of systematic reviews to determine the effects of hospital technologies on the quality, safety and efficacy of care demonstrated that, for the electronic prescriptions, substantially lesser evidence of medication errors was found, as well as greater compliance with the guidelines and better control of illnesses and better response time to the dispensing ${ }^{(14)}$.

The prescriptions should be comprehensive, in terms of the existence of information needed for all professionals who use them, as omitting information from the prescription can contribute to the occurrence of errors ${ }^{(13)}$. It should be kept in mind that error reporting by all health professionals, in combination with organizational changes, can favor patient safety and minimize medical errors ${ }^{(7)}$.

The engagement of different professionals in the various phases of the medication prescription process is essential, as reports on the occurrence of possible errors represent a possibility for learning, for the implementation of preventive measures, for high-quality care provision and for patient safety promotion through medication governance ${ }^{(15)}$.

To reduce the incidence of adverse events in public and private health services and promote safe medication usage practices, in the Brazilian literature, the Medication Prescription, Usage and Administration Safety Protocol stands out, which addresses safe practices for medication prescription, distribution and administration $^{(16)}$.

In view of the need for studies that identify the absence of information from the prescriptions and the lack of instruments in the literature, in this study, we intended to answer the following question: does a checklist permit verifying compliance with the safety recommendations concerning the structure of medication prescriptions?

Hence, considering that medication errors compromise the quality of care and patient safety, in this study, we aimed to elaborate a checklist to identify the compliance with recommendations for the structure of medication prescriptions, as well as to carry out the face and content validation and the reliability analysis.

\section{Method}

A methodological research was developed in three phases: construction of a tool to verify the safety in the medication prescription, face and content validation and reliability analysis.

To construct the instrument, the recommendations of the Medication Prescription, Usage and Administration Safety Protocol were used, coordinated by the Brazilian Health Department and the Brazilian Health Surveillance Agency (Anvisa), in partnership with Fundação Oswaldo Cruz (Fiocruz) and Fundação Hospitalar do Estado de Minas Gerais (Fhemig)(16). The tool constructed was called Lista de Verificação de Segurança na Prescrição 
de Medicamentos (Medication Prescription Safety Checklist - LVSPM) and covers identification data of the prescription and its medicines.

For the face and content validation, five multiprofesional judges were selected, being: one physician, one pharmacist and three nurses, all of whom held a Ph.D. and were experienced in the theme area of the research, four of them being faculty members at federal universities.

Initially, the judges were contacted by e-mail, inviting them to participate in the content validation phase of the LVSPM. After they had agreed, a document was forwarded with the description, purpose and objectives of the research, as well as the instrument, in order to assess whether it is measuring what it is intended to measure (face validation) and the relevance of each item in the construct studied (content validation)(17), that is, if both properly represent the hypothetic universe of the object, i.e. patient safety in medication prescription.

The reliability analysis was verified by means of the interrater method, by comparing two nurses' independent observations in the use of the checklist. The observations were made after training on the instrument and its applicability.

The study was developed at the medical and surgical clinical wards of a public teaching hospital in Uberaba, a city located in the interior of Minas Gerais, with a capacity of 37 and 65 beds, respectively. The choice of the wards was based on the feasibility criterion of the research, as they presented a computerized prescription system and a larger volume of prescriptions.

In the calculation of the sample size for the interrater reliability analysis, an expected Intraclass Correlation Coefficient (ICC) of 0.90 between the scores was considered, admitting coefficients not lower than ICC $=0.75$ for a $90 \%$ power, significance being set at $a=0.05$. Using the application PASS 2002 (Power Analysis and Sample Size), with these a priori coefficients, a sample size of $n=36$ prescriptions was obtained. Considering a $10 \%$ sampling loss, the maximum number of attempts would be 40 . Nevertheless, considering the losses in the data collection period, the final number of prescriptions analyzed was 27.

A pilot study was developed, using 15 prescriptions, to verify the adequacy of the validated checklist's contents to the reality of the information collection at the institution. Nevertheless, the measuring properties of the tool were not subject to statistical analysis in this phase, as the form and structure of the collection instrument underwent no changes.

The data were collected between July and September 2015, after the Medical Filing Service (Same) had provided the printed prescriptions. The
LVSPM was applied to the medication prescriptions of the units studied in order to identify compliance with the recommendations of the Health Department and Anvisa's Protocol. It is highlighted that, before the start of the data collection process, the judges were submitted to training for the sake of conformity of the data collection.

In the data analysis, the categorical variables were subject to univariate analyses through absolute and relative frequency tables. The interrater reliability was verified through the Kappa coefficient in the first part of the tool, as the variables are dichotomous, considering the correlation based on the magnitude of the agreement as low (0-0.20), regular (0.21-0.40), moderate (0.41-0.60), substantial (0.61-0.80) and almost perfect $(\geq 0.81)^{(18)}$, and the intraclass correlation coefficient as adequate when $>0.70^{(19)}$ in the second part, in view of the quantitative nature of the variable. Significance was set at 0.05 .

Approval for the research project was obtained from the Research Ethics Committee (Protocol 1.012.450), in compliance with Resolution 466/2012, which waived the signing of the Free and Informed Consent Form.

\section{Results}

The elaboration of the checklist was based on the items proposed in the protocol concerning the prescription, resulting in a first version with 27 items, divided in two parts: identification of the prescription (11 item) and medicines in the prescription (16 items).

The face and content validation of the LVSPM were verified by means of the interrater agreement, with a minimum consensus of $80 \%$. The judges analyzed this first version of the tool and their suggested modifications are displayed in Figure 1.

All of the experts' suggestions were executed because they were pertinent. After the changes, the final version of the LVSPM (Figure 2) contained 22 items, as items 9 and 10 were excluded and items 16, 24 and 27 were merged.

The first part of the checklist refers to the identification items of the medication prescription and contains nine items with three alternative answers and their respective codes: no (0); yes (1); does not apply (2), marking the most appropriate alternative with an X.

The second part, in turn, consists of 13 items related to the prescribed drugs, so that the code $M$ represents the medicine and an Arabic numeral its order in the prescription, e.g. M1 corresponds to Medicine 1 and so forth, according to the number ( $n$ ) of medicines in the prescription. The alternative answers are codes 0,1 , and 2 , which mean non-compliance, compliance and does not apply, respectively. The alternatives yes and no can receive code 1 , depending on the items that are to be assessed. 


\begin{tabular}{|c|c|c|}
\hline Item of LVSPM & Elaborated version & Judges' suggestions \\
\hline Item 1 & Full name of patient & Add "no abbreviations" \\
\hline Item 3 & Bed number & $\begin{array}{l}\text { Add "letter" of the bed; invert contents of Item } 3 \text { with Item } 4 \text { for logical } \\
\text { application sequence }\end{array}$ \\
\hline Item 7 & Signature of prescribing professional & Add "password" of the prescribing professional \\
\hline Item 9 & Full address of institution & Exclude the item \\
\hline Item 10 & Telephone of institution & Exclude the item \\
\hline Item 12 & No abbreviations & $\begin{array}{l}\text { Replace by "Has abbreviations (short names of medicines, units, } \\
\text { chemical formulae)" }\end{array}$ \\
\hline Items 13 and 27 & $\begin{array}{l}\text { Standardized abbreviations } \\
\text { Contains administration route }\end{array}$ & $\begin{array}{l}\text { Merge items } 13 \text { and } 27 \text { and replace by "Contains abbreviated } \\
\text { administration route in line with standardization at institution" }\end{array}$ \\
\hline Item 14 & Denominação Comum Brasileira & Add "standardized in" \\
\hline Items 15 and 16 & $\begin{array}{l}\text { No medicines with similar names } \\
\text { Highlight the writing of the distinctive part of the name }\end{array}$ & $\begin{array}{l}\text { Merge items } 15 \text { and } 16 \text { and replace by "Has medicines with similar } \\
\text { names identified in capital letters or bold print" }\end{array}$ \\
\hline Item 17 & Non-use of non-metric measures & $\begin{array}{l}\text { Replace by "Use expressions of non-metric measures (spoon, vial, } \\
\text { bottle)" }\end{array}$ \\
\hline Item 18 & Pharmaceutical form plus all necessary information & Add the necessary information (e.g. vial, bottle, pill) \\
\hline Item 19 & Microgram spelled out fully & $\begin{array}{l}\text { Replace by "Clearly indicated measuring unit, in case of microgram } \\
\text { spelled out fully" }\end{array}$ \\
\hline Item 20 & No use of points & Replace by "Use point instead of comma in the dosage prescription" \\
\hline Item 21 & No use of zero before comma & $\begin{array}{l}\text { Replace by "Use zero before the comma" (e.g. } 0.55 \mathrm{~g} \text { instead of } \\
500 \mathrm{mg})\end{array}$ \\
\hline Item 22 & $\begin{array}{l}\text { No use of expressions "continuing use" or "non-stop " } \\
\text { concerning length of treatment }\end{array}$ & $\begin{array}{l}\text { Replace by "Use expressions like 'continuing use' or 'non-stop' related } \\
\text { to the duration of treatment" }\end{array}$ \\
\hline Items 23 and 24 & $\begin{array}{l}\text { No use of vague expressions without indication of } \\
\text { maximum dose, dosage and usage conditions } \\
\text { Expression "if necessary" with dose, posology, maximum } \\
\text { daily dose and condition that determines the use or } \\
\text { interruption of the use }\end{array}$ & $\begin{array}{l}\text { Merge items } 23 \text { and } 24 \text {, replacing them by the expression 'if } \\
\text { necessary' with dosage, posology, maximum daily dose and condition } \\
\text { that determines the use or interruption of the use" }\end{array}$ \\
\hline Item 25 & Information about diluents & Add the word "contains" \\
\hline
\end{tabular}

Figure 1 - Changes suggested by expert committee to create the final version of the Medication Prescription Safety Checklist. Uberaba, MG, Brazil, 2015

To determine the compliance score, the answers with score 1 (one) are added up, according to the following formula: general compliance $=$ sum of total compliance percentages/total number of valid items. It is highlighted that, for items 1 to 9 , codes 1 are converted to $100 \%$. For items 10 to 22 , the compliance proportion is calculated by the sum of code 1 , divided by the number of valid items (total number of medicines - blank items), multiplying this result by 100. The checklist score ranges between 0 and 100, with higher scores indicating greater compliance.

It should be clarified that items 10,14, 17, 18 and 19 are considered inverted items. That is due to the fact that, the higher the instrument score, the greater the compliance with the recommendations. To calculate the compliance score, these items were scored 0 when the answer was yes and 1 when it was no. Thus, both options (yes and no) can receive code 1 , depending on the items that are to be assessed.

The reliability analysis was evidenced by means of the Kappa and ICC coefficients. In the first part of the checklist, items Q1 to Q9 were analyzed according to the results described in Table 1.

According to Table 1, the agreement index was perfect for items Q1, Q2 and Q7 $(K=1.00)$, with a statistically significant difference $(p<0.001)$.
Among the nine first items assessed, the Kappa coefficients and significance levels were not calculated for six (Q3, Q4, Q5, Q6, Q8 and Q9), as the results of the interrater agreement did not constitute a squared matrix.

The agreement proportion corresponded to $100 \%$ for all items in the first part of the instrument, that is, the judges agreed on all items of the 27 prescriptions analyzed.

Table 2 evidences the reliability analysis of the second part of the instrument, medicines on the prescription (items Q10 till Q22).

The data evidence that the ICC and significance level of items Q11, Q12, Q15, Q17, Q18 and Q20 could not be calculated as there was no variation among the observers, despite complete agreement.

Items Q14 (ICC=0.99), Q16 (ICC=0.99), Q19 (ICC $=0.85), \quad$ Q21 $\quad(\mathrm{ICC}=0.92)$ presented adequate reliability (ICC $>0.85)$ and are statistically significant $(p<0.001)$. Items $\mathrm{Q} 10$ and $\mathrm{Q} 22$ presented $\mathrm{ICC}=1.00$, with excellent reliability. Item Q13 (has medicines with similar names) did not present a compliance score as, in this item, for all medicines, code 2 (does not apply) was marked. Nevertheless, this item was not excluded because none of the prescriptions analyzed contained medicines with similar names, but these can be found at another time. As observed, the reliability of the LVSPM was excellent and statistically significant $(p<0001)$. 
LISTA DE VERIFICAÇÃO DE SEGURANÇA NA PRESCRIÇÃO DE MEDICAMENTOS - LVSPM

Prontuário n ${ }^{\circ}:$ Nome do Paciente:

Data da coleta de dados: ___

Clínica:

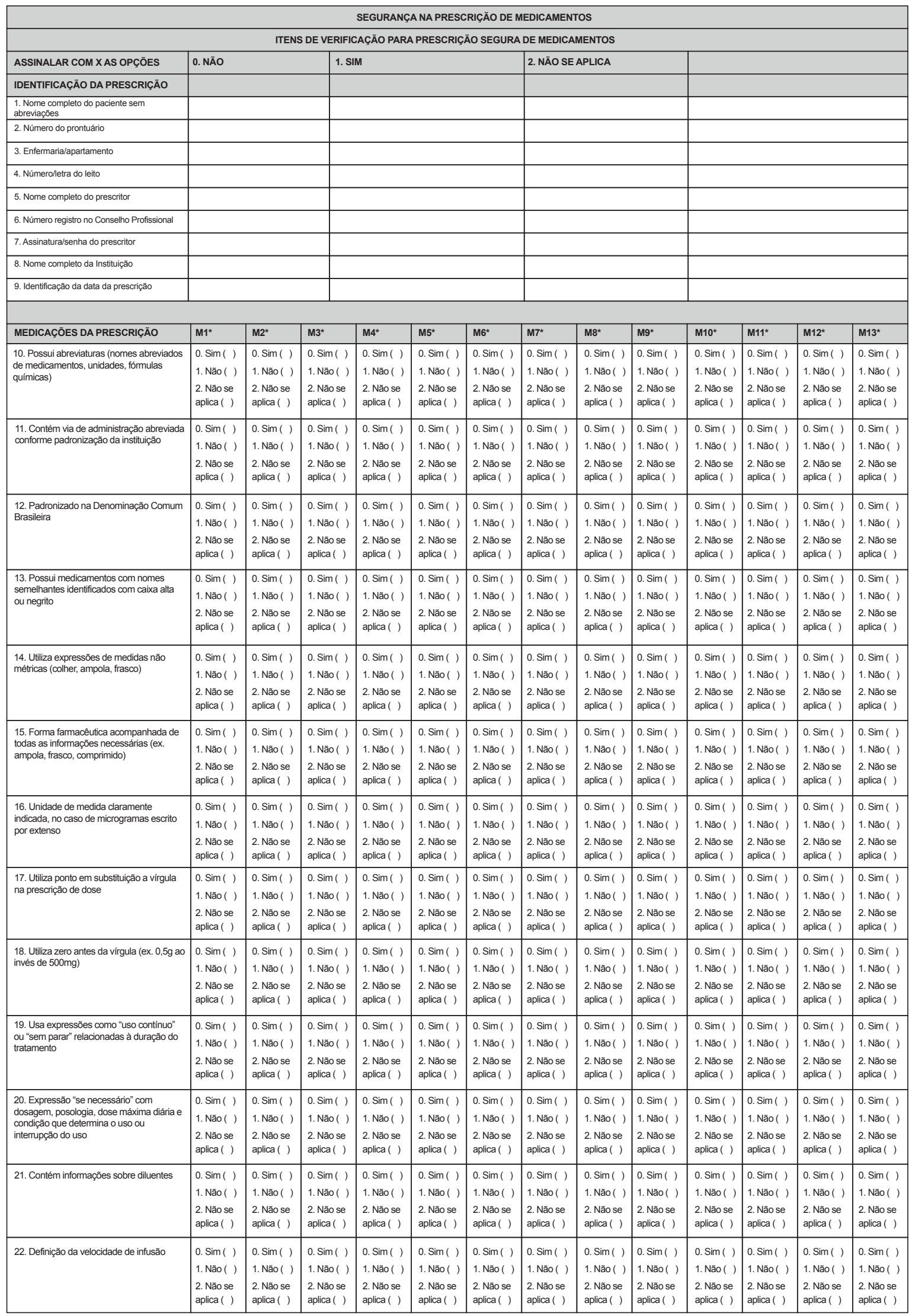

*M1, 2, 3, 4, 5, 6, 7, 8, 9 corresponde ao Medicamento 1, 2, 3, 4, 5, 6, 7, 8, 9, contido na prescriçăo médica.

Figure 2 - Final version of the Medication Prescription Safety Checklist. Uberaba, MG, Brazil, 2015 
Table 1 - Results of the interrater reliability analysis for items Q1 to Q9: identification of the prescription. Uberaba, MG, Brazil, 2015

\begin{tabular}{|c|c|c|c|c|c|c|c|c|c|c|c|}
\hline \multirow{3}{*}{ Identification of prescription } & \multicolumn{4}{|c|}{ Judge A } & \multicolumn{4}{|c|}{ Judge B } & \multirow{3}{*}{$\begin{array}{c}\mathrm{PC}^{*} \\
\%\end{array}$} & \multirow{3}{*}{$K^{\dagger}$} & \multirow{3}{*}{$p$} \\
\hline & \multicolumn{2}{|c|}{ No } & \multicolumn{2}{|c|}{ Yes } & \multicolumn{2}{|c|}{ No } & \multicolumn{2}{|c|}{ Yes } & & & \\
\hline & $\mathbf{N}$ & $\%$ & $\mathbf{N}$ & $\%$ & $\mathbf{N}$ & $\%$ & $\mathbf{N}$ & $\%$ & & & \\
\hline $\begin{array}{l}\text { Q1. Full name of patient without } \\
\text { abbreviations }\end{array}$ & 0 & 0 & 27 & 100 & 1 & 3.7 & 26 & 96.3 & 100 & 1.00 & $<0.001$ \\
\hline Q2. Patient file number & 0 & 0 & 27 & 100 & 1 & 3.7 & 26 & 96.3 & 100 & 1.00 & $<0.001$ \\
\hline Q3. Nursing ward/apartment & 0 & 0 & 27 & 100 & 0 & 0 & 27 & 100 & 100 & - & - \\
\hline Q4. Bed number/letter & 0 & 0 & 27 & 100 & 0 & 0 & 27 & 100 & 100 & - & - \\
\hline Q5. Full name of prescribing professional & 0 & 0 & 27 & 100 & 0 & 0 & 27 & 100 & 100 & - & - \\
\hline Q6. Professional board registration number & 0 & 0 & 27 & 100 & 0 & 0 & 27 & 100 & 100 & - & - \\
\hline Q7. Signature/password of prescriber & 0 & 0 & 27 & 100 & 1 & 3.7 & 26 & 96.3 & 100 & 1.00 & $<0.001$ \\
\hline Q8. Full name of institution & 27 & 100 & 0 & 0 & 27 & 100 & 0 & 0 & 100 & - & - \\
\hline Q9. Identification of prescription date & 0 & 0 & 27 & 100 & 0 & 0 & 27 & 100 & 100 & - & - \\
\hline
\end{tabular}

*Agreement proportion.

+Kappa coefficient.

Table 2 - Results of interrater reliability analysis for items Q10 till Q22: medicines on the prescription. Uberaba, MG, Brazil, 2015

\begin{tabular}{|c|c|c|c|c|c|c|}
\hline \multirow{2}{*}{ Medicines on the prescription } & \multicolumn{2}{|c|}{ Judge A } & \multicolumn{2}{|c|}{ Judge B } & \multirow{2}{*}{ ICC* } & \multirow{2}{*}{$\mathbf{p}$} \\
\hline & Mean & sd & Mean & sd & & \\
\hline Q10. Has abbreviations ${ }^{\dagger}$ & 29.65 & 21.92 & 29.65 & 21.92 & 1.00 & - \\
\hline $\begin{array}{l}\text { Q11. Contains abbreviated administration route as } \\
\text { standardized }\end{array}$ & 100.00 & 0.00 & 100.00 & 0.00 & - & - \\
\hline Q12. Standardized in Denominação Comum Brasileira & 100.00 & 0.00 & 100.00 & 0.00 & - & - \\
\hline Q13. Has medicines with similar names & - & - & - & - & - & - \\
\hline Q14. Uses non-metric measures ${ }^{\dagger}$ & 56.09 & 31.62 & 54.98 & 30.78 & 0.99 & $<0.001$ \\
\hline $\begin{array}{l}\text { Q15. Pharmaceutical form accompanied by all } \\
\text { necessary information }\end{array}$ & 0.00 & 0.00 & 0.00 & 0.00 & - & - \\
\hline Q16. Clearly indicated measuring unit & 55.68 & 32.30 & 54.57 & 31.00 & 0.99 & $<0.001$ \\
\hline $\begin{array}{l}\text { Q17. Uses point to replace comma in dose } \\
\text { prescription }^{\dagger}\end{array}$ & 100.00 & 0.00 & 100.00 & 0.00 & - & - \\
\hline Q18. Uses zero before the comma ${ }^{\dagger}$ & 100.00 & 0.00 & 100.00 & 0.00 & - & - \\
\hline $\begin{array}{l}\text { Q19. Uses expressions like "continuing use" or } \\
\text { "non-stop"† }\end{array}$ & 91.41 & 11.76 & 89.81 & 12.40 & 0.85 & $<0.001$ \\
\hline $\begin{array}{l}\text { Q20. Expression "if necessary" with all necessary } \\
\text { information }\end{array}$ & 0.00 & 0.00 & 0.00 & 0.00 & - & - \\
\hline Q21. Contains information about diluents & 46.53 & 32.54 & 47.63 & 33.24 & 0.92 & $<0.001$ \\
\hline Q22. Definition of infusion speed & 38.09 & 40.53 & 38.09 & 40.53 & 1.00 & - \\
\hline
\end{tabular}

*Intraclass Correlation Coefficient.

+ Yes $=0 /$ No=1 (to calculate compliance score).

\section{Discussion}

Other research results evidence the importance of using tools that permit the identification of possible prescription errors, contributing to improve the medication administration process, which involves different health professionals of relevant importance for the nursing team.

In one study, it was affirmed that prescribing correctly represents one of the essential skills to guarantee patient safety and, therefore, 74 medicine students were assessed in a study of the number of prescription errors committed in a prescription test.
These tests were assessed by means of a checklist to identify the prescription errors, evidencing that the students committed $69 \%$ of errors ${ }^{(10)}$.

In another study, the impact of introducing a prescription verification and correction checklist on the quality and safety of hospital prescriptions was assessed at two pediatric nursing wards of a university hospital in London, England. The technical and clinical prescription errors were assessed before and after the introduction of the checklist. The global technical error rate in the pre-intervention period was $10.8 \%$ and the clinical error rate $4.7 \%$. The most common errors were: lack of contact details for the physician and dose 
omissions. After the implementation of the verification and correction checklist, the error rates corresponded to 7.3 and $5.5 \%$, respectively. As for the clinical error, no significant impact of the intervention was detected. The researchers concluded that the implementation of a verification and correction checklist led to improvements in the quality of written prescriptions ${ }^{(20)}$.

A Chilean research also aimed to adapt and validate two checklists, one to measure the errors in handwritten prescriptions and the other to detect errors in the medication preparation process. The instruments were submitted to three phases: adaptation, as the instruments were based on the error classification of the National Coordinating Council for Medication Error Reporting and Prevention (NCCMERP); review by experts and reliability analysis. The checklists for medication prescription and dispensing consisted of 12 items to measure the prescription errors and seven to measure the preparation errors. The instruments showed to be valid and reliable(21).

To reduce the prescription errors, a French study is also highlighted, a pioneer in the development of a preliminary screening tool to identify omissions and inappropriate prescriptions in pediatrics, based on international and French guidelines(5).

In a different study, aiming to explore factors that provoke prevalent errors in hospitals tending towards medication errors, raising awareness about their existence and offering recommendations on how to minimize them to improve patient safety, 162 valid histories were analyzed for patients hospitalized at a public hospital in Ghana, based on a checklist to register possible medication errors. The results evidenced that: $60.5 \%$ of the patients did not receive the actual quantity of medicines; illegible writing; similar medication packages and labels; crowded workspace, besides distractions such as telephone ringing, interruption of one task to perform another and unnecessary conversation among the staff. The study highlighted the vulnerability of the medication process at the hospital in terms of medication errors and emphasized that, as part of a medication safety process, the hospitals should implement incident registration mechanisms, as a means to prevent the recurrence of medication errors(22).

In another study, the importance of reporting the medication errors was highlighted, as this represents a possibility to learn and implement preventive measures. In addition, the need for the safety culture in institutions was emphasized, where medication governance promotes patient safety and high-quality care provision ${ }^{(15)}$

The use of the LVSPM is recommended as a management tool in the nurses' clinical practice, offering support for the implementation of evidencebased care. The recommendations of a literature review corroborate this assertion, identifying evidence-based health care as a subculture of the patient safety culture. The best evidence-based practices include standardized processes, protocols, checklists and orientations, aspects that favor the safety culture ${ }^{(23)}$.

The application of a checklist like the LVSPM in daily work and the careful analysis of the results obtained can significantly improve the quality and safety of the medication therapy provided to the patients, besides guiding the professionals, especially the nurses to eliminate the errors deriving from the medication process $^{(24)}$

We consider that the predictive validity represents a limitation in this study. It should be highlighted though that this tool can be used in a subsequent study with a longitudinal and prospective design to estimate the predictive validity of complying with the recommendations, using the occurrence or not of medication-related adverse events as a criterion. We also consider that the LVSPM items refer to the practice at any healthcare level. Hence, future studies are needed to assess the use of the checklist in other contexts beyond the hospital.

\section{Conclusion}

In view of the above, the validity and reliability of the LVSPM were demonstrated. The checklist can be used in clinical practice, permitting the identification of prescription errors by nurses and other health professionals.

Judgments on the applicability in clinical practice depend on further research in different contexts. The LVSPM is a management instrument for clinical practice that can further the understanding of the needs to improve the prescriptions, resulting in the better quality of care, patient safety, evidence-based decision making by nurses and the reduction of medication-related errors.

\section{References}

1. Marques LFG, Romano-Lieber NS. Segurança do paciente no uso de medicamentos após a alta hospitalar: 
estudo exploratório. Saude Soc. 2014; 23(4):1431-44. doi: $10.1590 /$ S0104-12902014000400025

2. Freitas DF, Oda JY. Avaliação dos fatores de risco relacionados às falhas durante a administração de medicamentos. Arq Ciênc Saúde Unipar. [Internet]. 2008. [Acesso 20 set 2014];12(3):231-7. Disponível em: http://revistas.unipar.br/?journal=saude\&page $=$ article\& op=view\&path\%5B\%5D=2540\&path\%5B\%5D=1983

3. Gimenes FRE, Mota MLS, Teixeira TCA, Silva AEBC, Opitz SP, Cassiani SHB. Patient Safety in Drug Therapy and the Influence of the Prescription in Dose Errors. Rev. Latino- Am. Enfermagem. 2010;18(6):1055-61. doi: 10.1590/S0104-11692010000600003

4. Belela ASC, Pedreira MLG, Peterlini MAS. Erros de Medicação em Pediatria. Rev Bras Enferm. 2011; 64(3):563-69. doi: 10.1590/S0034-71672011000300022 5. Prot-Labarthe S, Weil T, Nguyen NPK, Berthe-Aucejo A, Angoulvant F, Boulkedid R, et al. Validation par consensus d'un outil d'identification de prescriptions inappropriées en pédiatrie (POPI). Arch Pédiatrie. 2016; 23(5):481-90. doi: 10.1016/j.arcped.2016.02.010

6. National Coordinating Council for Medication Error Reporting and Prevention (NCCMERP). About Medication Errors. What is a Medication Error? [Internet]. 2017 [cited Febr 12, 2017]; 74(4):668-75. Available from: http://www.nccmerp.org/about-medication-errors

7. Makary MA, Michael D. Medical error-the third leading cause of death in the US BMJ 2016; 353(i2139):2-5. doi: https://doi.org/10.1136/bmj.i2139

8. Lisby M, Nielsen LP, Brock B, Mainz J. How are medication errors defined? A systematic literature review of definitions and characteristics. Int J Qual Health Care. 2010; 22(6):507-18. doi: 10.1093/intqhc/mzq059.

9. Jacobsen TF, Mussi MM, Silveira MPT. Análise de erros de prescrição em um hospital da região sul do Brasil. Rev Bras Farm Hosp Serv Saúde São Paulo. [Internet]. 2015 [Acesso 12 fev 2017]; 6(3):23-6. Disponível em: http://www.sbrafh.org.br/rbfhss/public/ artigos/2015060304000800BR.pdf

10. Celebi N, Kirchhoff K, Lammerding-Köppel M, Riessen $R$, Weyrich P. Medical clerkships do not reduce common prescription errors among medical students. Naunyn Schmiedebergs Arch Pharmacol. 2010; 382(2):171-6. doi: 10.1007/s00210-010-0530-9

11. Néri EDR, Gadêlha PGC, Maia SG, Pereira AGS, Almeida PC, Rodrigues CRM, et al. Erros de Prescrição de Medicamentos em um Hospital Brasileiro. Rev Assoc Med Bras. 2011; 57(3):306-14. doi: 10.1590/S010442302011000300013
12. Franklin BD, Reynolds $M$, Shebl NA, Burnett $S$, Jacklin $A$. Prescribing errors in hospital inpatients: a three-centre study of their prevalence, types and causes. Postgrad Med J. 2011; 87(1033):739-45. doi: 10.1136/pgmj.2011.117879

13. Gimenes FRE, Marques TC, Teixeira TCA, Mota MLS, Silva AEBC, Cassiani SHB. Medication wrong-route administrations in relation to medical prescriptions. Rev. Latino-Am. Enfermagem. 2011; 19(1):11-7. doi: 10.1590/S0104-11692011000100003

14. Keasberry J, Scott IA, Sullivan C, Staib A, Ashby R. Going digital: a narrative overview of the clinical and organisational impacts of eHealth technologies in hospital practice. Aust Health Rev. 2017 Jan 9. doi: 10.1071/AH16233

15. Kavanagh C. Medication governance: preventing errors and promoting patient safety. Br J Nurs. 2017; 26(3):159-165. doi: 10.12968/bjon.2017.26.3.159

16. Agência Nacional de Vigilância Sanitária (ANVISA). Protocolo de segurança na prescrição, uso e administração de medicamentos. Brasília: MS; 2013. [Acesso 12 jun 2014]. Disponível em: http://www.hospitalsantalucinda. com.br/downloads/prot_meficamentos.pdf

17. Fayers PM, Machin D. Scores and measurements: validity, reliability, sensitivity. In: Fayers PM, Machin D. Quality of life: the assessment, analysis, and interpretation of patient-reported outcomes. 2nd ed. Chichester; Hoboken, New Jersey: J. Wiley; 2007. p. 77-108.

18. Landis JR, Koch GG. The measurement of observer agrément for categorical data. Biometrics. 1977;33(1):159-74.

19. Fleiss JL. The Design and Análysis of Clinical Experiments. Wiley: New York; 1986. 432p.

20. Lépée C, Klaber RE, Benn J, Fletcher PJ, Cortoos PJ, Jacklin A, Franklin BD. The use of a consultant-led ward round checklist to improve paediatric prescribing: an interrupted time series study. Eur J Pediatr. 2012; 171(8):1239-45. doi: 10.1007/s00431-012-1751-3

21. Alvarado AC, Ossa GX, Bustos ML. Adaptación y validación de instrumentos para medir errores en las recetas médicas y en el proceso de preparación de medicamentos en farmacia de pacientes ambulatorios. Rev Méd Chile. 2014;142(12):1547-52. doi: 10.4067/ S0034-98872014001200008

22. Koffuor GA, Anto BP, AbaiteY AK. Error-provoking conditions in the medication use process: the case of a government hospital in Ghana. J Patient Saf. 2012; 8(1):22-5. doi: 10.1097/PTS.0b013e31823d048d. 
23. Sammer CE, Lykens $K$, Singh KP, Mains DA, Lackan NA. What is patient safety culture? A review of the literature. J Nurs Scholarsh. 2010; 42(2):156-65. doi: 10.1111/j.1547-5069.2009.01330.x

24. Warholak TL, Rupp MT, Zale A, Hines M, Park S.J. Check it out: A practical tool for improving medication safety. Am Pharm Assoc. 2015; 55(6):621-5. doi: 10.1331/JAPhA.2015.14280 Creative Commons (CC BY).

This license lets others distribute, remix, tweak, and build upon your work, even commercially, as long as they credit you for the original creation. This is the most accommodating of licenses offered. Recommended for maximum dissemination and use of licensed materials. 